\title{
Ultrafast High-Repetition-Rate Waveguide Lasers
}

\author{
David P. Shepherd, Amol Choudhary, Alexander A. Lagatsky, Pradeesh Kannan, Stephen J. Beecher, \\ Robert W. Eason, Jacob I. Mackenzie, Xian Feng, Wilson Sibbett and C. Tom. A. Brown
}

\begin{abstract}
We report on progress in the field of integrated mode-locked waveguide lasers with an emphasis on compact monolithic designs producing picosecond and femtosecond optical pulses at multi-GHz repetition rates.
\end{abstract}

Index Terms - Integrated Optics, Lasers, Ultrafast Optics, Waveguides.

\section{INTRODUCTION}

$\mathrm{C}$ OMPACT sources of picosecond or femtosecond optical pulses with high repetition rates have applications in a diverse range of areas including communications [1], frequency-comb spectroscopy [2,3], optical sampling [4], and nonlinear microscopy [5]. Semiconductor lasers, in either edge-emitting [6] or surface-emitting [7] formats, modelocked fiber lasers [8], micro-ring resonators [9], and carefully engineered bulk laser systems [10] can all offer routes to sources of short pulses at multi-GHz repetition rates offering a range of attributes in terms of maximum repetition rate, average power, pulse duration, and stability. Within this field there is growing interest in waveguide lasers that can afford the potential for monolithic short cavities with fundamental mode-locked repetition rates of $\sim 10 \mathrm{GHz}$ [11], integrated components for passive mode-locking [12] and dispersion control [13], and gain media compatible with the generation of

Manuscript received May 29, 2015. This work was supported in part by the U.K. Engineering and Physical Sciences research Council under Grants EP/H035745/1, EP/L021390/1, and EP/J008052/1. A. Choudhary acknowledges an EPSRC doctoral prize.

D. P. Shepherd, S. J. Beecher, R. W. Eason, J. I. Mackenzie, and X. Feng are with the Optoelectronics Research Centre, University of Southampton, Southampton SO17 1BJ UK (e-mail: dps@orc.soton.ac.uk; S.J.Beecher@soton.ac.uk: $\quad$ rwe@orc.soton.ac.uk; $\quad$ jim@orc.soton.ac.uk; xif(orc.soton.ac.uk).

A. Choudhary was with the University of Southampton, Southampton SO17 1BJ UK. He is now with the Centre for Ultrahigh bandwidth Devices for Optical Systems (CUDOS), School of Physics, University of Sydney, Sydney NSW 2006, Australia (email: a.choudhary@physics.usyd.edu.au).

P. Kannan was with the University of Southampton, Southampton SO17 1BJ UK. He is now with the Department of Physics, Govt. Victoria College, Palakkad, Kerala 678001, India (email: pradeeshk@victoriacollege.in).

C. T. A. Brown and W. Sibbett are with the SUPA, School of Physics and Astronomy, University of St Andrews, North Haugh, St Andrews, KY16 9SS, UK (email: ctab@st-andrews.ac.uk; ws@st-andrews.ac.uk).

A. A. Lagatsky was with the University of St Andrews, North Haugh, St Andrews, KY16 9SS, UK. He is now with the Fraunhofer Centre for Applied Photonics, Technology and Innovation Centre, 99 George Street, Glasgow, G1 1RD, UK (email: alexander.lagatsky@fraunhofer.co.uk). femtosecond pulses [14] and high average powers [15,16]. The waveguide geometry also lends itself to integrated diodepumping [17], spatial mode control [18] and efficient heat removal [19].

In this paper we will review the progress to date in the area of ultrafast waveguide lasers. We will discuss potential gain media for such systems, the fabrication techniques that can be used to make suitable low-loss devices, the integration of components for pulse production and dispersion control, and the results achieved so far with high-repetition rate integrated waveguide laser systems.

\section{Ultrafast WAVEguide Gain MEDIA}

The wide variety of integrated-optics fabrication techniques has allowed low-propagation-loss waveguides to be produced in a broad range of gain media. Many of these media have been shown to be suitable for the production of ultrashort pulses.

\section{A. Rare-Earth-Doped Glasses}

Low-loss $(\sim 0.1 \mathrm{~dB} / \mathrm{cm})$ channel and planar waveguides are commonly produced in rare-earth-doped glasses via ion exchange. In a typical process, a sodium-rich glass is placed in a salt melt containing potassium and/or silver ions that diffuse into the glass in exchange for sodium ions, leading to a local change in refractive index that can be used to form optical waveguides. Appropriate photolithographical patterning techniques permit the fabrication of both planar (1dimensional confinement) and single-mode channel devices. The glasses used for exchange can be compatible with relatively high rare-earth doping levels for short devices and hence high fundamental repetition rates when mode-locked as monolithic devices. Rare-earth dopant emission spectra in glasses are also typically broader than in crystal hosts, allowing the generation of ultrashort pulses. Ion-exchanged glass waveguide lasers based on $\mathrm{Nd}^{3+}, \mathrm{Yb}^{3+}, \mathrm{Er}^{3+}$, and $\mathrm{Tm}^{3+}$ [20-23] have all been demonstrated. Other techniques for glass waveguide laser production include flame-hydrolysis deposition (FHD) [24], rf sputtering [25] and laser inscription [26].

\section{B. $\mathrm{Ti}^{3+}$-Doped Sapphire}

Titanium-doped sapphire is the most prominent bulk laser system for broad tunability and the generation of ultrashort pulses. Typically, it requires pumping by argon-ion lasers or frequency-doubled diode-pumped solid-state lasers and has a 
relatively large threshold power requirement, although recent advances have paved the way for directly diode-pumped systems to be produced [27]. Consequently, there has been significant interest in creating low-loss optical waveguides in this material to deliver compact low-threshold devices. Fabrication techniques for sapphire planar waveguides include pulsed laser deposition (PLD), ion in-diffusion, ionimplantation, and laser inscription [28-31] and several waveguide laser demonstrations have been made [14, 32]. However, to date propagation losses remain relatively high, typically at the $\sim 1 \mathrm{~dB} / \mathrm{cm}$ level.

\section{Rare-Earth-Doped Potassium Double-Tungstates}

The potassium double-tungstates, $\mathrm{KGd}\left(\mathrm{WO}_{4}\right)_{2}$ (KGW), $\mathrm{KY}\left(\mathrm{WO}_{4}\right)_{2} \quad(\mathrm{KYW})$, and $\mathrm{KLu}\left(\mathrm{WO}_{4}\right)_{2} \quad(\mathrm{KLW})$, offer a combination of broad absorption and emission spectra with large absorption and emission cross-sections when doped with rare-earth ions, as well as the possibility of high doping levels. They therefore represent strong competitors to Ti:sapphire as bulk gain media for ultrashort laser systems that allow simple diode-pumped devices. Optical waveguides have been fabricated in these materials by a number of different techniques including PLD, ion-implantation, laser inscription, and liquid-phase epitaxy (LPE) [33-36]. Highly efficient $\mathrm{Yb}^{3+}$ and $\mathrm{Tm}^{3+}$ doped waveguide lasers have been demonstrated based on LPE growth [37,38], which can deliver low-loss waveguides and high-optical-confinement by co-doping with Gd [39].

\section{Rare-Earth-Doped Sesquioxides}

$\mathrm{Yb}$-doped sesquioxides $\mathrm{Y}_{2} \mathrm{O}_{3}$ (yttria), $\mathrm{Sc}_{2} \mathrm{O}_{3}$ (scandia), and $\mathrm{Lu}_{2} \mathrm{O}_{3}$ (lutetia) have higher thermal conductivity, broader emission spectra, and stronger absorption than the ubiquitous $\mathrm{Y}_{3} \mathrm{Al}_{5} \mathrm{O}_{12}$ (YAG), making them a good choice for high-power ultrafast bulk lasers [40]. Optical waveguides have been fabricated in sesquioxides (or mixed sesquioxides) by PLD, atomic layer deposition, and thermal evaporation [41-43], and waveguide laser operation has been demonstrated in $\mathrm{Nd}^{3+}$, $\mathrm{Yb}^{3+}$, and $\mathrm{Tm}^{3+}$ doped crystals [44-46], with propagation losses as low as $\sim 1 \mathrm{~dB} / \mathrm{cm}$.

\section{E. Rare-Earth-Doped Garnets}

The widespread prominence of garnets and especially YAG as gain host crystals for bulk lasers has led to a wide interest in creating waveguides in such a material. Successful fabrication techniques have included ion implantation, LPE, PLD, laser inscription, and contact bonding [47-51]. In particular, contact bonding is especially interesting as it allows dissimilar materials to be bonded together to produce low-loss $(\sim 0.1$ $\mathrm{dB} / \mathrm{cm}$ ) multi-layered structures with high numerical apertures, forming double-clad and large-mode-area structures and allowing high-power diode-pumped operation in a similar fashion to fiber lasers [52]. While emission spectra tend to be narrower than in glasses, double-tungstates, or sesquioxides, femtosecond pulses can be generated at high powers in bulk Yb:YAG lasers [53].

\section{F. Chromium-Doped Gain Media}

$\mathrm{Cr}^{2+}, \mathrm{Cr}^{3+}$, and $\mathrm{Cr}^{4+}$ doped gain media offer the potential for short-pulse devices across a broad spectral range from the near- to mid-IR. Notably, waveguide lasers have been demonstrated in $\mathrm{Cr}^{2+}: \mathrm{ZnSe}$, fabricated by PLD and laser inscription [54,55], in $\mathrm{Cr}^{2+}: \mathrm{ZnS}$ fabricated by laser inscription [56], and in $\mathrm{Cr}^{4+}:$ YAG [57], although the latter is in a crystal fiber rather than a planar geometry.

\section{G. Rare-Earth-Doped Lithium Niobate}

There are a number of low-loss $(\sim 0.1 \mathrm{~dB} / \mathrm{cm})$ waveguide fabrication techniques, such as proton-exchange and Tiindiffusion, which have been developed for $\mathrm{LiNbO}_{3}$ due to exceptional electro-optical, acousto-optical, and nonlinearoptical properties that make it an excellent platform for integrated optics. It is also readily doped with rare-earth ions by thermal indiffusion and numerous waveguide lasers have been demonstrated based on $\mathrm{Nd}^{3+}, \mathrm{Yb}^{3+}, \mathrm{Er}^{3+}$, and $\mathrm{Tm}^{3+}[58-$ 61].

\section{INTEGRATED SWITCHING ELEMENTS AND DISPERSION CONTROL}

While both active and passive techniques have been used in integrated formats to produce pulsed waveguide laser systems, passive techniques tend to be predominant due to their ease of integration and production of shorter pulses. Actively modelocked lasers have been demonstrated in $\mathrm{Er}: \mathrm{LiNbO}_{3}$ waveguide lasers by depositing electrodes on the surface of the crystal to form an integrated travelling-wave phase modulator for frequency-modulated mode-locking [62]. Active mode-locking has also been achieved in an $\mathrm{Er}^{3+}$-doped silica waveguide by integration with a $\mathrm{LiNbO}_{3}$ modulator via fiber-pigtails [63].

Passive mode-locking of waveguide laser systems has been demonstrated with semiconductor saturable absorbing mirrors (SESAMs), carbon nanotubes (CNTs), and graphene, [64-66], and as soliton fiber ring lasers with a planar gain element [67]. Some of these demonstrations are based on extended freespace or fiber-pigtailed cavities to enable fiber-coupled modelocking components [65] or active control for reduction of timing jitter [68]. However, to achieve the highest fundamental repetition rates, short monolithic or quasimonolithic cavities are desirable. This can be achieved by end-butting the mode-locking element (e.g. SESAM or graphene-coated mirror) as part of the waveguide laser cavity or by evanescent-field coupling to layers deposited on the waveguide upper surface (e.g. CNT or graphene layers). The latter technique has the better potential for power-scaled output by avoiding the high intensities associated with in-line intra-cavity elements, although it may be more difficult to achieve sufficient fluence to saturate the absorption.

The use of monolithic cavities also demands integrated dispersion control if the shortest mode-locked pulses are to be achieved. To date, this has been realized by using material in the waveguide structure with specific dispersion properties [69] and through introducing a small gap between the end-face of the waveguide and the cavity mirror to form an effective Gires-Tournois (GT) interferometer [70]. The first method has similar disadvantages to non-monolithic cavities in that the cavity length is significantly increased leading to lowered 
fundamental pulse repetition rates, whereas the second is only quasi-monolithic and is prone to instability due to the need to accurately control the gap between the end-face and the cavity mirror. Future solutions could include mirrors or SESAMs with designer dispersion properties or similarly designed integrated feedback gratings $[72,73,13]$. Figure 1 shows a schematic view of a waveguide with various options for integrated passive mode-locking and dispersion control.

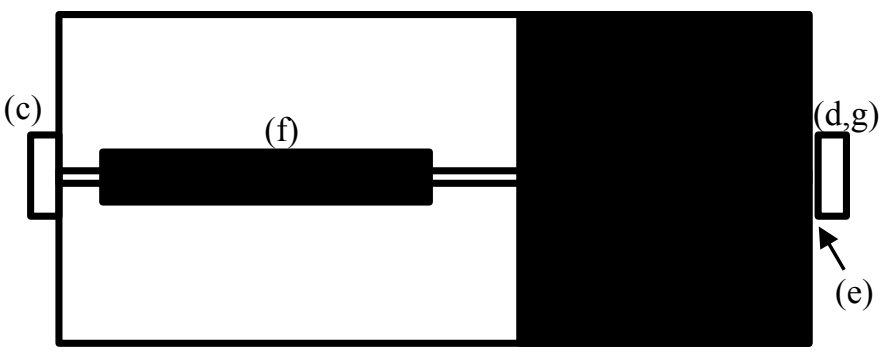

Fig. 1. Schematic channel waveguide structure top-view showing options for integrated dispersion compensation: (a) Material dispersion (b) chirped Bragg reflector (c) dispersion designed SESAM (d) chirped mirror (e) GT interferometer gap; and integrated mode-locking: (c) SESAM (f) graphene or CNT overlayer $(\mathrm{g})$ graphene-coated mirror

Pulse repetition rates greater than the fundamental rate set by the cavity length may be obtained in an integrated fashion via harmonic mode-locking [73] or pulse multiplication elements [74]. However, the former can suffer from supermode-competition noise requiring integrated stabilization [75] and both add to the overall complexity of the device.

\section{High-RePETITION RATE INTEGRATEd MODE-LOCKED WAVEGUIDE LASERS}

In this section we will review experimental progress to date in ultrafast high-repetition rate lasers that exploit an integrated monolithic, or quasi-monolithic, geometry and operate in

TABLE I

Ultrafast High-REPETITION-RATE INTEGRATED WAVEGUIDE LASERS

\begin{tabular}{llccc}
\hline \multicolumn{1}{c}{ System } & \multicolumn{1}{c}{ Method } & PRF/GHz & $\begin{array}{c}\tau_{F W H M} \\
/ \mathrm{ps}\end{array}$ & Regime \\
\hline Er:LiNbO 3 [75] & $\begin{array}{l}\text { Active Harmonic } \\
\text { FM }\end{array}$ & 10 & 5.7 & CWML \\
& Active Harmonic & 6.3 & 5.2 & CWML \\
$\begin{array}{l}\text { Er:Silicate Glass } \\
\text { [63] }\end{array}$ & AM & & & \\
$\begin{array}{l}\text { Er:Silicate Glass } \\
\text { [69] }\end{array}$ & Passive SESAM & 0.4 & 0.44 & CWML \\
$\begin{array}{l}\text { Yb:Phosphate Glass } \\
\text { [11] }\end{array}$ & Passive SESAM & 15.2 & 0.81 & CWML \\
$\begin{array}{l}\text { Yb,Er:Phosphate } \\
\text { Glass [12,76] }\end{array}$ & $\begin{array}{l}\text { Passive SESAM } \\
\text { Passive Graphene }\end{array}$ & 6.8 & 5.4 & CWML \\
$\begin{array}{l}\text { Yb:Bismuthate } \\
\text { Glass [66] }\end{array}$ & Passive Graphene & 1.5 & 1.06 & QSML \\
$\begin{array}{l}\text { Tm:YAG Ceramic } \\
\text { [77] }\end{array}$ & Passive Graphene & 7.8 & $<100$ & QSML \\
\end{tabular}

PRF $=$ Pulse Repetition Frequency, $\tau_{F W H M}=$ Full-Width Half-Maximum Pulse Duration either a Q-switched and mode-locked (QML) or a continuouswave mode-locked (CWML) regime. Table 1 summarizes the results obtained to date.

\section{A. Continuous-Wave Mode-Locked Waveguide Lasers}

A fully integrated mode-locked waveguide laser operating at $\mathrm{GHz}$ repetition rates was demonstrated as early as 1993 by Suche et al. [62]. This device was based on a $\mathrm{LiNbO}_{3}$ substrate, with the rare-earth doping and the waveguides fabricated by thermal indiffusion of erbium and titanium respectively. The laser cavity was formed by e-beam evaporation of alternating $\mathrm{SiO}_{2}$ and $\mathrm{TiO}_{2}$ layers to form mirrors on the end-faces of the waveguide. Active modelocking at the fundamental repetition rate of $1.441 \mathrm{GHz}$ was obtained with an integrated travelling-wave phase modulator fabricated by evaporating and photolithographically patterning gold electrodes onto the surface of the $\mathrm{LiNbO}_{3}$ substrate. These devices were developed further, pushing to higher repetition rates through harmonic mode-locking [73] and incorporating passive low-finesse coupled cavities for supermode stabilization and pulse repetition rate multiplication [75]. Repetition rates as high as $10 \mathrm{GHz}$ were achieved for near-bandwidth-limited 5.7 ps Gaussian pulses, at a wavelength of $1562 \mathrm{~nm}$ and output powers of $\sim 8 \mathrm{~mW}$.

Integrated mode-locked waveguide lasers have also been constructed by pigtailing the various elements (waveguide gain medium, mode-locking element, output coupling, etc.) of the laser together using optical fibers such that free-space propagation is eliminated. Della Valle et al. [65] have incorporated a fiber-pigtailed CNT-polymer saturable absorber into a ring cavity with a femtosecond laser inscribed $\mathrm{Yb}$,Erdoped phosphate glass waveguide gain medium. 1.8-ps nearbandwidth-limited $\operatorname{sech}^{2}$ pulses were obtained, but the rather long fiber-pigtailed cavity led to repetition rates of just 16.74 MHz. It should be noted that a fiber-pigtailed Yb,Er-doped phosphate glass waveguide laser fabricated by ion exchange [67] has been mode-locked by exploiting nonlinear polarization rotation to achieve pulse durations as short as 116 fs but this involved the use of non-integrated free-space elements. A high-repetition-rate mode-locked fiber-pigtailed waveguide laser system was demonstrated by Kawanishi et al. [63], again employing harmonic active mode-locking. In this case a $\mathrm{LiNbO}_{3}$ amplitude modulator was coupled to an Erdoped silica waveguide and 5.2 ps pulses were obtained at repetition rates of $6.3 \mathrm{GHz}$ with average powers of $0.5 \mathrm{~mW}$.

The first fully integrated passively mode-locked waveguide laser was demonstrated by Byun et al. [69]. The gain medium was a 5-cm-long Er-doped alumino-silicate waveguide fabricated by radio-frequency (RF) sputtering onto an oxidized silicon substrate, with etched channels and a silica upper cladding. The waveguide chip had a number of further integrated features, as shown schematically in Fig.2, including a $20-\mathrm{cm}$ section of phosphorous-doped silica waveguide to control the overall group-velocity dispersion, a loop mirror to provide output coupling, a butted SESAM, an on-chip pumpcoupling waveguide, and fiber-coupled pump delivery to the 
chip. The looped mirror configuration allowed the relatively long total cavity length $(25 \mathrm{~cm})$ to be fabricated on a chip of just a few square centimeters. The device delivered pulses as short as 440 fs although the relatively long cavity length required for this method of dispersion compensation limited the repetition rate to $394 \mathrm{MHz}$. It was also shown that the monolithic design leads to low-timing-jitter operation, with a $10 \mathrm{kHz}$ to $20 \mathrm{MHz}$ integrated value of $24 \mathrm{fs}$.

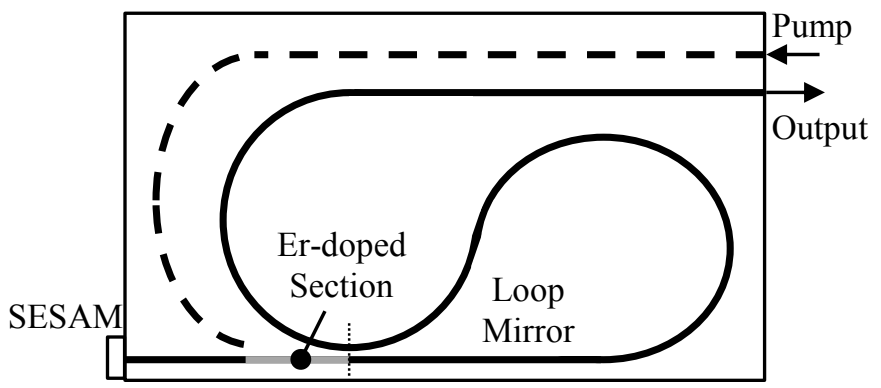

Fig. 2. Fully integrated, passively mode-locked waveguide laser schematic design [69].

Higher output powers and repetition rates were demonstrated within our group [70,11] for a series of passively mode-locked waveguide lasers, but in a less sophisticated configuration where a SESAM and bulk output coupling mirror were simply butted to the end-faces of the waveguide to form the laser cavity. The waveguides used in these experiments were fabricated by $\mathrm{K}^{+} / \mathrm{Ag}^{+}$ion exchange in a 12 wt.\% Yb-doped IOG-1 phosphate glass (Schott Glass Technologies Inc.) creating an index change of $6.6 \times 10^{-3}$ and a diffusion depth of $\sim 13.8 \mu \mathrm{m}$. Figure 3 shows a typical configuration for diode-laser pumped experiments, where a single-mode fiber-coupled diode pump laser is coupled into the waveguide with free-space optics.

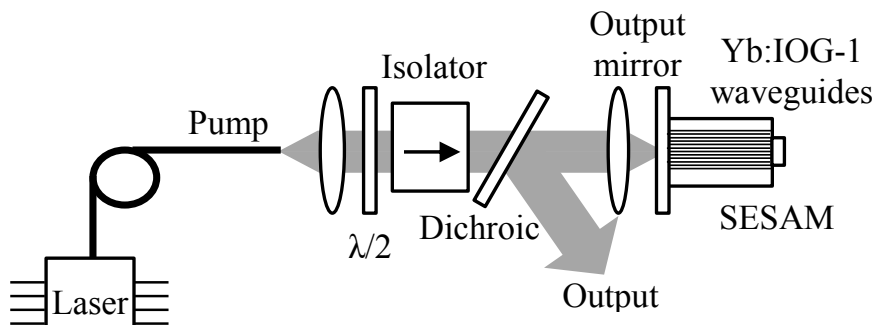

Fig. 3. Free-space diode-pumping arrangement for a passively modelocked waveguide laser [70].

To obtain mode-locking with this set up it was found that it was necessary to introduce a small gap $(\sim 10 \mu \mathrm{m})$ between the end-face of the waveguide and the SESAM (or output mirror). We believe this gap introduced sufficient negative groupvelocity dispersion, via a GT interferometer effect, to allow soliton formation, as discussed later. Figure 4 shows the output versus input characteristics for a 20 -mm-long sample, using a 4-\%-transmission output coupler and a SESAM (Batop $\mathrm{GmbH}$ ) with an initial reflectivity of $99.3 \%$ at $1050 \mathrm{~nm}$, a $0.4-$ $\%$ modulation depth, a saturation fluence of $90 \mu \mathrm{J} / \mathrm{cm}^{2}$ and a relaxation time of $0.5 \mathrm{ps}$.

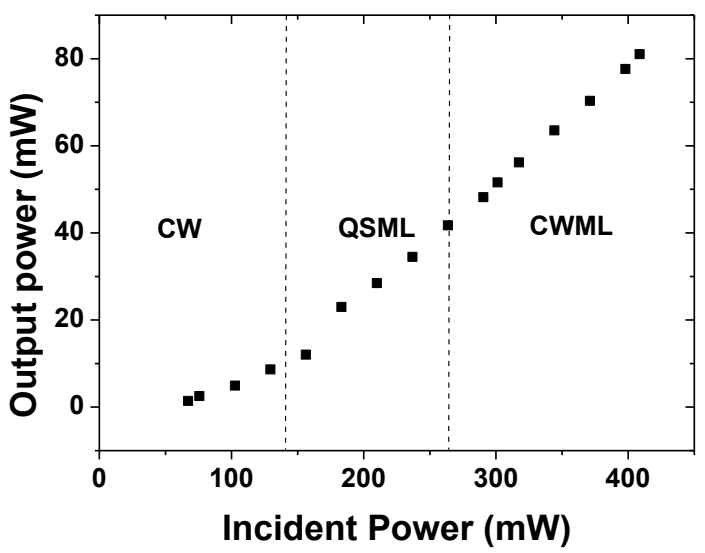

Fig. 4. Output power characteristics for a passively mode-locked Ybdoped glass waveguide laser [70].

As is commonly observed for such operation, continuouswave $(\mathrm{CW})$ output was obtained near the lasing threshold, followed by a QSML regime, and finally the desired CWML regime. At higher powers pulse break-up was observed. The intensity autocorrelation and corresponding optical spectrum of the pulses at the maximum stable output power of $81 \mathrm{~mW}$ are shown in Fig. 5. A sech ${ }^{2}$ fit suggested a pulse-duration of 800 fs and a time-bandwidth product of 0.46 .

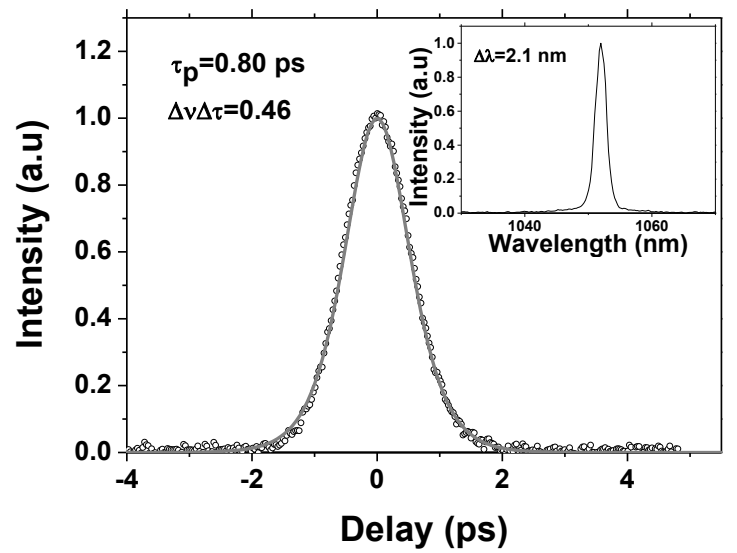

Fig. 5. Autocorrelation trace for a passively mode-locked Yb-doped glass waveguide laser (grey line is a $\operatorname{sech}^{2}$ fit). Inset shows corresponding optical spectrum [70].

The RF spectrum of the pulse train was measured with a fast InGaAs photodiode (11 GHz bandwidth) and an RF spectrum analyzer, with the results shown in Fig. 6. A clean peak was observed at the fundamental pulse repetition frequency of $4.926 \mathrm{GHz}$, with a $60-\mathrm{dB}$ signal-to-noise ratio and no observable side-peaks, indicating excellent pulse-topulse stability and a lack of Q-switching instabilities. The wide-span RF-spectrum measurements (inset) indicated 
single-pulse operation.

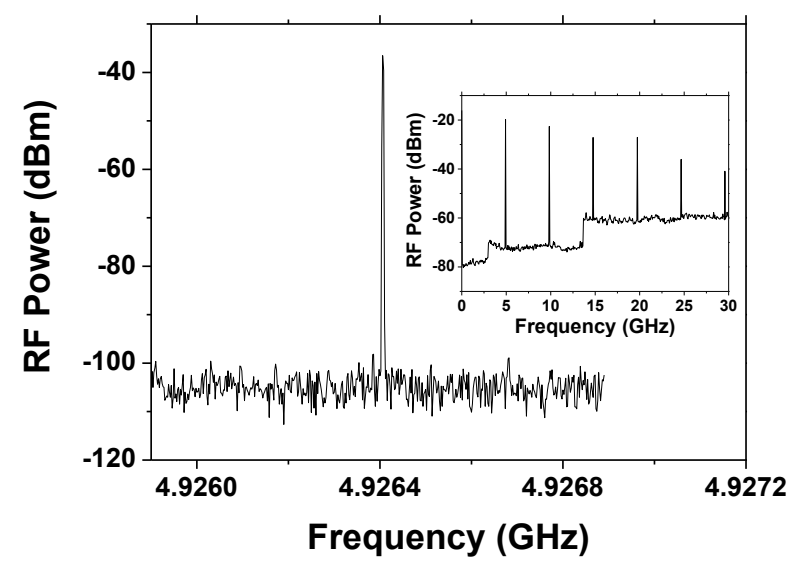

Fig. 6. RF spectrum showing the fundamental repetition frequency of a passively mode-locked $\mathrm{Yb}$-doped glass waveguide laser measured with a resolution bandwidth of $1 \mathrm{kHz}$. The inset shows the broader span spectrum at a resolution bandwidth of $1 \mathrm{MHz}$. The stepwise increase observed in the baseline is an instrument artefact when the RF analyser is operated over large frequency ranges. [70].

We attributed the observed femtosecond pulses to a soliton formation mechanism, where the phase shift due to self-phase modulation (SPM) in the waveguides is balanced by negative group velocity dispersion (GVD) originating from an equivalent GT interferometer due to the micron-sized gap, as expressed below [78],

$$
\frac{\delta E_{p}}{4 \tau}=\frac{|D|}{\tau^{2}}
$$

where $\delta$ is the SPM nonlinear coefficient, $E_{p}$ is the intracavity pulse energy, $D$ is the GVD, and $\tau$ is related to the fullwidth-half-maximum pulse duration by $\tau_{F W H M}=1.76 \tau$. This led to an estimate of the net GVD of $\sim-4000 \mathrm{fs}^{2}$. Such a dispersion would be available from the equivalent GT interferometer structure [79] but there is a very sensitive variation in its value, crucially dependent upon the gap size, which would require precise control to sub- $\mu \mathrm{m}$ precision if this method was to be applied in any practical devices. Further evidence that a soliton mode-locking regime had been achieved came from the low experimental value of the critical pulse energy required to avoid Q-switching instabilities $(\sim 0.2$ $\mathrm{nJ})$ compared to that predicted without soliton effects [10] $(\sim 3.6 \mathrm{~nJ})$. Such a large reduction in the critical energy is consistent with a soliton mode-locking regime [80].

Higher repetition rates, up to $15.2 \mathrm{GHz}$, with similar pulse durations, bandwidths, and output powers, were obtained by using waveguides of different lengths (down to $6.5 \mathrm{~mm}$ ) [11]. The limit on repetition rate will come about partly due to the need to use a length sufficient to absorb the pump light and partly due to the need to reach critical pulse energies within the cavity to avoid the QSML regime. Similar techniques were also employed to mode-lock a Yb,Er-doped IOG-1 phosphate glass producing pulses of $\sim 2$ to 5 ps in duration, at repetition rates up to $6.8 \mathrm{GHz}$ and output powers of $30 \mathrm{~mW}$ [76]. A fine tuning of the repetition rate over $\sim 1 \mathrm{MHz}$, attributed to thermal expansion, was also demonstrated as the pump power was varied.

\section{B. Q-Switched and Mode-Locked Waveguide Lasers}

Passively mode-locked lasers will operate in the QSML regime if they have not reached the critical steady-state intracavity pulse energy required for CWML operation. However, the higher mode-locked pulse energies and intensities associated with Q-switching could have potential applications in areas such as nonlinear frequency conversion and materials processing, although care must be taken to ensure that the energy contained within the Q-switched envelope does not cause damage to the mode-locking element when combined with the small spot sizes typical for single-mode waveguides.

QSML operation of a laser-inscribed Yb-doped bismuthate glass waveguide laser was achieved by Mary et al. [66] in a similar configuration to that shown in Fig. 3 except that a graphene-coated output coupling mirror was used instead of a SESAM. The 45-nm-thick graphene film was fabricated on the output coupling mirror from a filtered dispersion of graphite flakes. Raman spectroscopy of the dispersion and graphene film showed that although significant D and D' bands were present, indicating multi-layered flakes, they were electronically decoupled and behaved as a collection of single layers. The final film is estimated to contain 40 layers, has a saturation fluence of $10.2 \mu \mathrm{J} / \mathrm{cm}^{2}$, a $17.6-\%$ modulation depth, and a $30-\%$ non-saturable loss. A high average output power of $202 \mathrm{~mW}$ was achieved with a slope efficiency of $48 \%$, delivering near-transform-limited 1.06-ps-duration $\mathrm{sech}^{2}$ pulses at a $1.5-\mathrm{GHz}$ repetition rate within a Q-switched envelope that reached repetition rates of $0.95 \mathrm{MHz}$.

A similar experiment was implemented for a laser-inscribed ceramic Tm-doped YAG waveguide laser by Ren et al. [77] to achieve QSML operation at $1943 \mathrm{~nm}$. The nonlinearity of the graphene layer was measured with a 100 -fs optical parametric amplifier at $2 \mu \mathrm{m}$ giving a $59-\mu \mathrm{Jcm}^{-2}$ saturation fluence and a modulation depth of $8.4 \%$. A maximum output power of 6.5 $\mathrm{mW}$ was obtained at a slope efficiency of $2 \%$. The Qswitched envelope had a repetition rate up to $684 \mathrm{kHz}$ and contained mode-locked pulses at a fundamental repetition rate of $7.8 \mathrm{GHz}$.

In collaboration with researchers at the University of Pittsburgh, we have also demonstrated QSML operation of waveguide lasers based on graphene-coated mirrors [12]. Ionexchanged Yb,Er-doped IOG-1 phosphate glass was used as the waveguide gain medium, cut and polished to a length of $14.5 \mathrm{~mm}$. In this case the graphene layer, fabricated at Pittsburgh, was grown by atmospheric pressure chemical vapor deposition (APCVD) on large-domain ultra-flat copper substrates [81] and then transferred onto a 2-\%-transmission (at $1057 \mathrm{~nm}$ ) output coupling mirror. Figure 7 shows the Raman spectrum of the graphene-coated mirror. The upper trace is for a similar coating on a $1535-\mathrm{nm}$ mirror, which is included as the higher reflectivity of this mirror at the Raman pump wavelength of $532 \mathrm{~nm}$ led to a higher signal-to-noise 
ratio. The observation of two distinct peaks at $2687 \mathrm{~cm}^{-1}$ (2D) and $1584 \mathrm{~cm}^{-1}(2 \mathrm{D})$, along with the Lorentzian shape of the 2D peak indicated that a single-layer graphene film was present on the output mirrors. The comparison of the optical transmission spectra of the graphene-coated and uncoated mirrors indicated a $\sim 2.3-\%$ decrease in transmission due to the graphene layer, which was again consistent with a single-layer coating.

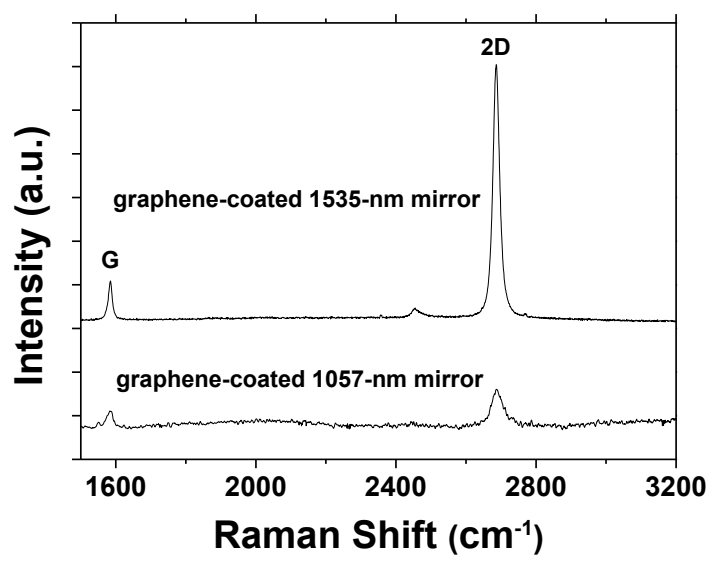

Fig. 7. Raman spectra of APCVD-grown graphene layers transferred to output coupling mirrors at $1535 \mathrm{~nm}$ and $1057 \mathrm{~nm}$ [12].

The experimental arrangement was again similar to that shown in Fig. 3, but with the SESAM replaced with the graphene-coated output coupling mirror. QSML operation was confirmed by observing the RF spectrum with a $12.5 \mathrm{GHz}$ detector and an RF spectrum analyzer, as shown in Fig. 8. Mode-locking at a fundamental repetition rate of $6.8 \mathrm{GHz}$ was observed and the relatively broad peak, for example in comparison to Fig. 6, is consistent with QSML operation. The Q-switched envelope and mode-locked train of pulses was observed with a $50 \mathrm{GHz}$ oscilloscope, confirming QSML operation at $6.8 \mathrm{GHz}$. Q-switching repetition rates up to 526 $\mathrm{kHz}$ were observed and a maximum average power of $27 \mathrm{~mW}$ was measured at a slope efficiency of $5 \%$.

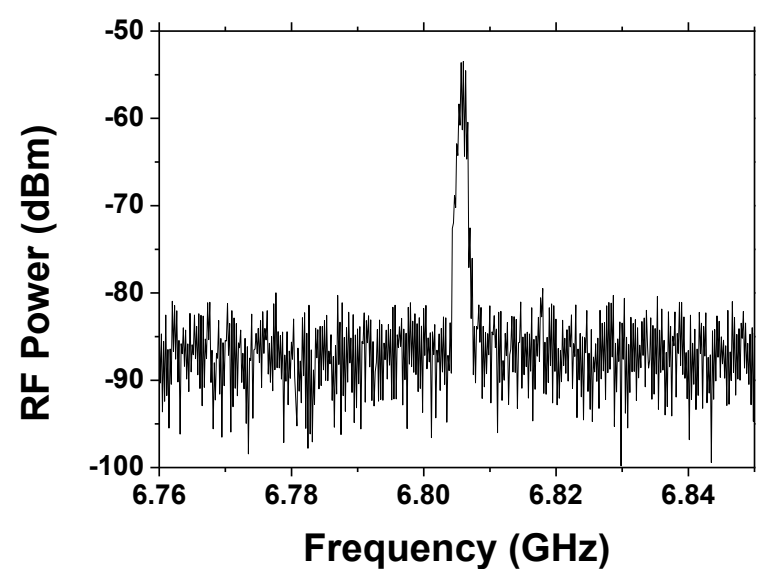

Fig. 8. RF spectrum for a Q-switched mode-locked waveguide laser [12].

\section{CONCLUSION}

A range of actively and passively mode-locked waveguide lasers has been demonstrated by several research groups, delivering ultrashort pulses at multi-GHz repetition rates based on a variety of fabrication techniques, mode-locking elements, and dispersion control methods. Sub-picosecond pulses have been demonstrated by passive mode-locking, with fundamental repetition rates up to $15 \mathrm{GHz}$, limited by the need to reach critical intra-cavity pulse energies to avoid Qswitching instabilities and the need for sufficient length of gain medium to efficiently absorb the pump light. Repetition rates could be increased beyond this limit, while maintaining a compact monolithic design, by employing integrated pulse multiplication methods [74]. Currently, average output powers are also limited by the use of single-mode channel waveguides pumped by diode-lasers with maximum pump powers of $\sim 1 \mathrm{~W}$. There are also potential damage considerations through the use of saturable absorbers against the end-faces of the waveguide. One potential method of overcoming these limitations is to use planar waveguides, with guidance in just one dimension, which would allow pumping by higher-power diode lasers [15] and exploiting evanescentfield coupling to saturable absorbers on the top surface of the waveguide. Towards this goal, we have recently demonstrated a PLD-grown Yb-doped-yttria planar waveguide pumped by a broad-area diode laser delivering up to $6 \mathrm{~W}$ to the waveguide. An APCVD-grown graphene layer was transferred to the upper surface of the waveguide and Q-switched output was obtained at average powers approaching $0.5 \mathrm{~W}$ [82]. An alternative approach to power scaling would be to adopt a master-oscillator-power-amplifier configuration, either using further high-power planar-waveguide amplifiers [83] or utilizing optical-fiber amplifiers [84].

\section{ACKNOWLEDGEMENT}

The authors wish to acknowledge Brian D'Urso and Shonali Dhingra for the fabrication of the APCVD graphene films, and Tina Parsonage and James Grant-Jacob for the fabrication of PLD-grown yttria. The data for this paper can be found at http://dx.doi.org/10.5258/SOTON/377316.

\section{REFERENCES}

[1] Y. J. Chai, C. G. Leburn, A. A. Lagatsky, C. T. A. Brown, R. V. Penty, I. H. White, and W. Sibbett, "1.36-Tb/s spectral slicing source based on a $\mathrm{Cr}^{4+}$-YAG femtosecond laser," J. Lightw. Technol., vol. 23, pp. 13191324, 2005.

[2] S. A. Diddams, L. Hollberg, and V. Mbele, "Moelecular finferprinting with the resolved modes of a femtosecond laser frequency comb," Nature, vol. 445, pp. 627-630, 2007.

[3] C.-H. Li, A. J. Benedick, P. Fendel, A. G. Glenday, F. X. Kärtner, D. F. Phillips, D. Sasselov, A. Szentgyorgyi, and R. L. Walsworth, "A laser frequency comb that enables radial velocity measurements with a precision of $1 \mathrm{~cm} \mathrm{~s}^{-1}$," Nature, vol. 452, pp.610-612, 2008.

[4] A. Bartels, R. Cerna, C. Kistner, A. Thoma, F. Hudert, C. Janke, and T. Dekorsy, "Ultrafast time-domain spectroscopy based on high-speed asynchronous optical sampling," Rev. Sci. Instrum., vol. 78, 035107, 2007.

[5] S.-W. Chu, T.-M. Liu, and C.-K. Sun, "Real-time second-harmonicgeneration microscopy based on a $2-\mathrm{GHz}$ repetition rate Ti:sapphire laser," Opt. Express, vol. 11, pp. 933-938, 2003. 
[6] L. Hou, E. A. Avrutin, M. Haji, R. Dylewicz, A. C. Bryce, and J. H. Marsh, "160 GHz passively mode-locked AlGaInAs $1.55 \mu \mathrm{m}$ strained quantum-well lasers with deeply etched intracavity mirrors," IEEE $J$. Select. Top. In Quantum Electron., vol. 19, 1100409, 2013.

[7] U. Keller and A. C. Tropper, "Passively modelocked surface-emitting semiconductor lasers," Phys. Reports, vol. 429, pp. 67-120, (2006).

[8] A. Martinez and S. Yamashita, "Multi-gigahertz repetition rate passively modelocked fiber lasers using carbon nanotubes," Opt. Express, vol. 19, pp. $6155-6163,2011$

[9] A. Pasquazi, M. Peccianti, B. E. Little, S. T. Chu, D. J. Moss, and R. Morandotti, "Stable, dual mode, high repetition rate mode-locked laser based on a microring resonator," Opt. Expresss, vol. 20, pp. 27355$27362,2012$.

[10] L. Krainer, R. Paschotta, S. Lecomte, M. Moser, K. J. Weingarten, and U. Keller, "Compact Nd: $\mathrm{YVO}_{4}$ lasers with pulse repetition rates up to $160 \mathrm{GHz}, "$ IEEE J. Quantum Electron., vol. 38, pp. 1331-1338.

[11] A. A. Lagatsky, A. Choudhary, P. Kannan, D. P. Shepherd, W. Sibbett, and C. T. A. Brown, "Fundamentally mode-locked, femtosecond waveguide oscillators with multi-gigahertz repetition frequencies up to 15 GHz," Opt. Express, vol. 21, pp. 19608-19614, 2013.

[12] A. Choudhary, S. Dhingra, B. D'Urso, P. Kannan, and D. P. Shepherd, "Graphene Q-switched mode-locked and Q-switched ion-exchanged waveguide lasers," IEEE Photon. Technol. Lett., vol. 27, pp. 646-649, 2015.

[13] C. Sima, J. C. Gates, H. L. Rogers, P. L. Mennea, C. Holmes, M. N. Zervas, and P. G. R. Smith, "Ultra-wide detuning planar Bragg grating fabrication technique based on direct UV grating writing with electrooptic phase modulation," Opt. Express, vol. 21, pp. 15747-15754, 2013.

[14] M. Pollnau, C. Grivas, L. Laversenne, J. S. Wilkinson, R. W. Eason, and D. P. Shepherd, "Ti:Sapphire waveguide lasers," Laser Phys. Lett., vol. 4, pp. 560-571, 2007

[15] D. P. Shepherd, S. J. Hettrick, C. Li, J. I. Mackenzie, R. J. Beach, S. C. Mitchell, and H. E. Meissner, "High-power planar dielectric waveguide lasers," J. Phys. D.: Appl. Phys., vol. 34, pp. 2420-2432, 2001.

[16] D. Filgas, T. Clatterbuck, M. Cashen, A. Daniele, S. Hughes, and D. Mordaunt, "Recent results for the Raytheon RELI program,"in Proc. SPIE 8381, Laser Technology for Defense and Security VIII, 83810W (May 7, 2012); doi:10.1117/12.921055.

[17] R. J. Beach, S. C. Mitchell, H. E. Meissner, O. R. Meissner, W. F. Krupke, J. M. McMahon, W. J. Bennett, and D. P. Shepherd, "CW and Passively Q-switched Cladding-Pumped Planar Waveguide Lasers," Opt. Lett., vol. 26, pp. 881-883, 2001.

[18] T. Bhutta, J. I. Mackenzie, and D. P. Shepherd, "Spatial dopant profiles for transvers-mode selection in multimode waveguides," J. Opt. Soc. Am. B, vol. 19, pp. 1539-1543, 2002.

[19] J. I. Mackenzie, C. Li, D. P. Shepherd, R. J. Beach, and S. C. Mitchell, "Modeling of high-power continuous-wave Tm:YAG side-pumped double-clad waveguide lasers," IEEE J. Quantum Electron., vol. 38, pp. 222-230, 2002

[20] N. A. Sanford, K. J. Malone, and D. R. Larson, "Integrated-optic laser fabricated by field-assisted ion exchange in neodymium-doped sodalime-silicate glass," Opt. Lett., vo. 15, pp. 366-368, 1990.

[21] C. Florea and K. A. Winick, "Ytterbium-doped glass waveguide laser fabricated by ion exchange," J. Lightwave Technol., vol. 7, pp. 15931601,1999

[22] T. Feuchter, E. K. Mwarania, J. Wang, L. Reekie, and J. S. Wilkinson, "Erbium-doped ion-exchanged waveguide lasers in BK-7 glass," IEEE Photon. Tech. Lett., vol. 4 , pp. 542-544, 1992.

[23] A. Choudhary, P. Kannan, J. I. Mackenzie, X. Feng, and D. P. Shepherd, "Ion-exchanged $\mathrm{Tm}^{3+}$ :glass channel waveguide laser," Opt. Lett., vol. 38, pp. 1146-1148, 2013.

[24] Y. Hibino, T. Kitagawa, M. Shimizu, F. Hanawa, and A. Sugita, "Neodymium-doped silica optical waveguide lasers on silicon substrate," IEEE Photon. Tech. Lett., vol. 1, pp. 349-350, 1989.

[25] Y. C. Yan, A. J. Faber, H. de Waal, P. G. Kik, and A. Polman, "Erbiumdoped phosphate glass waveguide on silicon with $4.1 \mathrm{~dB} / \mathrm{cm}$ gain at 1.535 um," Appl. Phys. Lett., vol. 71, pp. 2922-2924, 1997.

[26] R. Osellame, N. Chiodo, G. D. Valle, G. Cerullo, R. Ramponi, P. Laporta, A. Killi, U. Morgner, and O. Svelto, "Waveguide lasers in the C-band fabricated by laser inscription with a compact femtosecond oscillator," IEEE J. Select. Top. In Quantum Electron., vol. 12, pp. 277285, 2006.

[27] P. W. Roth, A. J. Maclean, D. Burns, and A. J. Kemp, "Direct diodelaser pumping of a mode-locked Ti:sapphire laser," Opt. Lett., vol. 36, pp. 304-306, 2011
[28] A. A. Anderson, R. W. Eason, M. Jelinek, C. Grivas, D. Lane, K. Rogers, L. M. B. Hickey, and C. Fotakis, "Growth of Ti:sapphire single crystal thin films by pulsed laser deposition," Thin Solid Films, vol. 300, pp. 68-71, 1997.

[29] V. Apostolopoulos, L. M. B. Hickey, D. A. Sager, and J. S. Wilkinson, "Gallium-diffused waveguides in sapphire," Opt. Lett., vol. 26, pp. $1586-1588,2001$

[30] L. D. Morpeth, J. C. McCallum, and D. N. Jamieson, "Structural characterization of Ti;sapphire regions formed by localized high-energy implantation of Ti and O ions," Nucl. Instr. and Meth in Phys. Res. B, vol. 181, pp. 372-376, 2001.

[31] V. Apostolopoulos, L. Laversenne, T. Colomb, C. Depeursinge, R. P. Salathé, M. Pollnau, R. Osellame, G. Cerullo, and P. Laporta, "Femtosecond-irradiation-induced refractive-index changes and channel waveguideing in bulk $\mathrm{Ti}^{3+}$ :Sapphire," Appl. Phys. Lett., vol. 85, pp. 1122-1124, 2004.

[32] C. Grivas, C. Corbari, G. Brambilla, and P. G. Lagoudakis," Tunable, continuous-wave Ti:sapphire channel waveguide lasers written by femtosecond and picosecond laser pulses," Opt. Lett., vol. 37, pp. 46304632,2012

[33] P. A. Atanasov, R. I. Tomov, J. Perriére, R. W. Eason, N. Vainos, A. Klini, A. Zherikhin, and E. Millon," Appl. Phys. Lett., vol. 76, pp. 24902492, 2000.

[34] Y. Jiang, K.-M. Wang, X.-L. Wang, C.-L. Jia, J.-X. Zhang, J.-Y. Wang, H.-J. Ma, R. Nie, and D.-Y. Shen, "Optical waveguide formed in $\mathrm{Yb}: \mathrm{KLu}\left(\mathrm{WO}_{4}\right)_{2}$ crystal by $6.0 \mathrm{MeV} \mathrm{O}^{+}$implantation," Chin. Phys. Lett., vol. 23, pp. 922-924, 2006.

[35] C. N. Borca, V. Apostolopoulos, F. Gardillou, H. G. Limberger, M. Pollnau, and R. P. Salathé, "Buried channel waveguides in Yb-doped $\mathrm{KY}\left(\mathrm{WO}_{4}\right)_{2}$ crystals fabricated by femtosecond laser irradiation," Appl. Surf. Sci., vol. 253, pp. 8300-8303, 2007.

[36] M. Pollnau, Y. E. Romanyuk, F. Gardillou, C. N. Borca, U. Greibner, S. Rivier, and V. Petrov, "Double tungstate lasers: From bulk toward onchip integrated waveguide devices," IEEE J. Select. Top. In Quantum Electron., vol. 13, pp. 661-671, 2007.

[37] Y. E. Romanyuk, C. N. Borca, M. Pollnau, S. Rivier, V. Petrov, and U. Greibner, "Yb-doped $\mathrm{KY}\left(\mathrm{WO}_{4}\right)_{2}$ planar waveguide laser," Opt. Lett., vol. 31, pp. 53-55, 2006.

[38] K. van Dalfsen, S. Aravazhi, C. Grivas, S. M. García-Blanco, and M. Pollnau, "Thulium channel waveguide laser with $1.6 \mathrm{~W}$ of output power and $~ 80 \%$ slope efficiency," Opt. Lett., vol. 39, pp. 4380-4383, 2014.

[39] D. Geskus, S. Aravazhi, E. Bernhardi, C. Grivas, S. Harkema, K. Hametner, D. Günther, K. Wörhoff, and M. Pollnau, "Low-threshold, highly efficient $\mathrm{Gd}^{3+}, \mathrm{Lu}^{3+}$ co-doped $\mathrm{KY}\left(\mathrm{WO}_{4}\right)_{2}: \mathrm{Yb}^{3+}$ planar waveguide lasers," Laser Phys. Lett., vol. 6, pp. 800-805, 2009.

[40] C. R. E. Baer, C. Kränkel, C. J. Saraceno, O. H. Heckl, M. Golling, R. Peters, K. Petermann, T. Südmeyer, G. Huber, and U. Keller, "Femtosecond thin-disk laser with $141 \mathrm{~W}$ of average power," Opt. Lett., vol. 35, pp. 2302-2304, 2010

[41] S. Zhang and R. Xiao, "Yttrium oxide films prepared by pulsed laser deposition," J. Appl. Phys., vol. 83, pp. 3842-3848, 1998.

[42] T. T. Van and J. P. Chang, "Controlled erbium incorporation and photoluminescence of Er-doped $\mathrm{Y}_{2} \mathrm{O}_{3}$, , Appl. Phys. Lett., vol. 87, 011907, 2005.

[43] L. Rabisch, S. Bär, and H. Scheife, "Eu-doped $(\mathrm{Lu} / \mathrm{Sc})_{2} \mathrm{O}_{3}$ thin films grown by thermal evaporation," Opt. Mat., vol. 28, pp. 665-670, 2006.

[44] A. Kahn, S. Heinrich, H. Kühn, K. Petermann, J. D. B. Bradley, K. Wörhoff, M. Pollnau, and G. Huber,"Low threshold monocrystalline $\mathrm{Nd}$ :(Gd,Lu $)_{2} \mathrm{O}_{3}$ channel waveguide laser,“ Opt. Express, vol. 17, pp. 4412-4418, 2009

[45] H. Kühn, S. Heinrich, A. Kahn, K. Petermann, J. D. B. Bradley, K. Wörhoff, M. Pollnau, and G. Huber,"Monocrystalline $\mathrm{Yb}^{3+}:(\mathrm{Gd}, \mathrm{Lu})_{2} \mathrm{O}_{3}$ channel waveguide laser at $967.8 \mathrm{~nm}$," Opt. Lett., vol. 34, pp. 27182720,2009

[46] J. W. Szela, K. A. Sloyan, T. L. Parsonage, J. I. Mackenzie, and R. W. Eason, "Laser operation of a Tm: $\mathrm{Y}_{2} \mathrm{O}_{3}$ planar waveguide laser," Opt. Express, vol. 21, pp. 12460-12468, 2013.

[47] S.J.Field, D.C.Hanna, D.P.Shepherd, A.C.Tropper, P.J.Chandler, P.D.Townsend and L.Zhang, "Ion-Implanted Nd:YAG Waveguide Lasers," IEEE J. Quantum. Electron., vol. 27, pp. 428-433, 1991.

[48] I.Chartier, B.Ferrand, D.Pelenc, S.J.Field, D.C.Hanna, A.C.Large, D.P.Shepherd, and A.C.Tropper, "Growth and Low Threshold Laser Oscillation of an Epitaxially Grown Nd:YAG Waveguide," Opt. Lett., vol. 17, pp. 810-812, 1992. 
[49] C.L.Bonner, A.A.Anderson, R.W.Eason, D.P.Shepherd, D.S.Gill, C.Grivas, and N.Vainos, "Performance of a Low Loss Pulsed Laser Deposited $\mathrm{Nd}: \mathrm{Gd}_{3} \mathrm{Ga}_{5} \mathrm{O}_{12}$ Waveguide Laser at $1.06 \mu \mathrm{m}$ and $0.94 \mu \mathrm{m}$," Opt. Lett., vol. 22, pp. 988-990, 1997.

[50] A. G. Okhrimchuk, A. V. Shestakov, I. Khrushchev, and J. Mitchell, "Depressed cladding, buried waveguide laser formed in a YAG: $\mathrm{Nd}^{3+}$ crystal by femtosecond laser writing," Opt. Lett., vol. 30, pp. 2248-2250, 2005.

[51] C.T.A.Brown, C.L.Bonner, T.J.Warburton, D.P.Shepherd, A.C.Tropper, D.C.Hanna, and H.E.Meissner, "Thermally Bonded Planar Waveguide Lasers," Appl. Phys. Lett., vol. 71, pp. 1139-1141, 1997.

[52] C.L.Bonner, T.Bhutta, D.P.Shepherd, and A.C.Tropper, "Double-Clad Structures and Proximity Coupling for Diode-Bar-Pumped Planar Waveguide Lasers," IEEE J. Quantum Electron., vol. 36, pp. 236-242, 2000.

[53] W. Schneider, A. Ryabov, Cs. Lombosi, T. Metzger, Zs. Major, J. A. Fülöp, and P. Baum, " $800-\mathrm{fs}, 330-\mu \mathrm{J}$ pulses from a $100-\mathrm{W}$ regenerative $\mathrm{Yb}: \mathrm{YAG}$ thin-disk amplifier at $300 \mathrm{kHz}$ and $\mathrm{THz}$ generation in $\mathrm{LiNbO}_{3}$," Opt. Lett., vol. 39, 6604-6607, 2014.

[54] J. E. Williams, V. V. Federov, D. V. Martyshkin, I. S. Moskalev, R. P. Camata, and S. B. Mirov, "Mid-IR laser oscillation in $\mathrm{Cr}^{2+}: \mathrm{ZnSe}$ planar waveguide," Opt. Express, vol. 18, pp. 25999-26006, 2010.

[55] J. Macdonald, S. Beecher, P. Berry, G. Brown, K. Schepler, and A. Kar, "Efficient mid-infrared Cr:ZnSe channel waveguide laser operating at 2486 nm," Opt. Lett., vol. 38, pp. 2194-2196, 2013.

[56] J. R. Macdonald, S. J. Beecher, A. Lancaster, P. A. Berry, K. L. Schepler, S. B. Mirov, and A. K. Kar, "Compact Cr:ZnS channel waveguide laser operating at $2333 \mathrm{~nm}$," Opt. Express, vol. 22, pp. 70527057, 2014.

[57] S. Ishibashi and K. Naganuma, "Mode-locked operation of $\mathrm{Cr}^{4+}: \mathrm{YAG}$ single-crystal fiber laser with external cavity," Opt. Express, vol. 22, pp. 6746-6771, 2014.

[58] M. Hempstead, J. S. Wilkinson, and L. Reekie, "Waveguide lasers operating at $1084 \mathrm{~nm}$ in neodymium-diffused lithium niobate," IEEE Photon. Tech. Lett., vol. 4, pp. 853-855, 1992.

[59] J. K. Jones, J. P. de Sandro, M. Hempstead, D. P. Shepherd, A. C. Large, A. C. Tropper, and J. S. Wilkinson, "Channel waveguide laser at $1 \mu \mathrm{m}$ in Yb-indiffused $\mathrm{LiNbO}_{3}$," Opt. Lett., vol. 20, pp. 1477-1479, 1995.

[60] C. Becker, T. Oesselke, J. Pandavenes, R. Riken, K. Rochhausen, G. Schreiber, W. Sohler, H. Suche, R. Wessel, S. Balsamo, I. Montrosset, and D. Sciancalepore, "Advanced Ti:Er: $\mathrm{LiNbO}_{3}$ waveguide lasers," IEEE J. Select. Top. in Quantum Electron., vol. 6, pp. 101-113, 2000.

[61] J. P. de Sandro, J. K. Jones, D. P. Shepherd, M. Hempstead, J. Wang, and A. C. Tropper, "Non-photorefractive cw Tm-indiffused $\mathrm{Ti}: \mathrm{LiNbO}_{3}$ waveguide laser operating at room temperature," IEEE Photon. Tech. Lett., vol. 8, pp. 209-211, 1996.

[62] H. Suche, L. Baumann, D. Hiller, and W. Sohler, "Modelocked Er:Ti:LiNbO ${ }_{3}$ waveguide laser," Elec. Lett., vol. 29, pp. 1111-1112, 1993.

[63] S. Kawanishi, K. Hattori, H. Takara, M. Oguma, O. Kamatani, and Y. Hibino, "Actively modelocked ring laser using Er-doped silica-based planar waveguide amplifier," Elec. Lett., vol. 31, pp. 363-364, 1995.

[64] E. R. Thoen, E. M. Koontz, D. J. Jones, D. Barbier, F. X. Kärtner, E. I. Ippen, and L. A. Kolodziejski, "Erbium-ytterbium waveguide laser mode-locked with a semiconductor saturable absorber mirror," Photon. Tech. Lett., vol. 12, pp. 149-151, 2000.

[65] G. D. Valle, R. Osellame, G. Galzerano, N. Chiodo, G. Cerullo, P. Laporta, O. Svelto, U. Morgner, A. G. Rozhin, V. Scardaci, and A. C. Ferrari, "Passive mode locking by carbon nanotubes in a femtosecond laser written waveguide laser ," Appl. Phys. Lett., vol. 89, 231115, 2006.

[66] R. Mary, G. Brown, S. J. Beecher, F. Torrisi, S. Milana, D. Popa, T. Hasan, Z. Sun, E. Lidorikis, S. Ohara, A. C. Ferrari, and A. K. Kar, "1.5 $\mathrm{GHz}$ picosecond pulse generation from a monolithic waveguide laser with a graphene-film saturable output coupler," Opt. Express, vol. 21, pp. 7943-7950, 2013.

[67] D. J. Jones, S. Namiki, D. Barbier, E. P. Ippen, and H. A. Haus, "116-fs soliton source based on an Er-Yb codoped waveguide amplifier," Photon. Tech. Lett., vol. 10, pp. 666-668, 1998.

[68] J. B. Schlager, B. E. Callicoatt, R. P. Mirin, and N. A. Sanford, "Passively mode-locked glass waveguide laser with 14 -fs timing jitter," Opt.Lett., vol. 28, pp. 2411-2413, 2003.

[69] H. Byun, D. Pudo, S. Frolov, A. Hanjani, J. Shmulovich, E. P. Ippen, and F. X. Kärtner, "Integrated low-jitter 400-MHz, femtosecond waveguide laser," IEEE Photon. Tech. Lett., vol.21, pp. 763-765, 2009.
[70] A. Choudhary, A. A. Lagatsky, P. Kannan, W. Sibbett, C. T. A. Brown, and D. P. Shepherd, "Diode-pumped femtosecond solid-state waveguide laser with a $4.9 \mathrm{GHz}$ pulse repetition rate," Opt. Lett., vol.37, pp. 44164418, 2012.

[71] R. Szipöcs, K. Ferencz, C. Spielmann, and F. Krausz, "Chirped multilayer coatings for broadband dispersion control in femtosecond lasers," Opt. Lett., vol. 19, pp. 201-203, 1994.

[72] M. Moenster, W. Richter, and G. Steinmeyer, "Resonant saturable absorber mirrors for dispersion control in ultrafast lasers," IEEE $J$. Quantum Electron., vol. 43, pp. 174-181, 2007.

[73] H. Suche, A. Greiner, W. Qui, R. Wessel, and W. Sohler, "integrated optical Ti:Er:LiNbO 3 soliton source," IEEE J. Quantum Electron., vol. 33, pp. 1642-1646, 1997.

[74] M. Y. Sander, S. Frolov, J. Shmulovich, E. P. Ippen, and F. X. Kärtner,” Opt. Express, vol. 20, pp. 4102-4113, 2012.

[75] R. Wessel, R. Ricken, K. Rochhausen, H. Suche, and W. Sohler, "Supermode stabilized coupled-cavity 5- and $10-\mathrm{GHz}$ mode-locked Ti:Er:LiNbO ${ }_{3}$ waveguide lasers," IEEE J. Quantum Electron., vol. 36, pp. 394-398, 2000.

[76] A. Choudhary, A. A. Lagatsky, Z. Y. Zhang, K. J. Zhou, Q. Wang, R. A. Hogg, K. Pradeesh, E. U. Rafailov, W. Sibbett, C. T. A. Brown, and D. P. Shepherd, "A diode-pumped $1.5 \mu \mathrm{m}$ waveguide laser mode-locked at 6.8 GHz by a quantum dot SESAM," Laser Phys. Lett., vo. 10, 105803, 2013.

[77] Y. Ren, G. Brown, R. Mary, G. Demetriou, D. Popa, F. Torrisi, A. C. Ferrari, F. Chen, and A. K. Kar, "7.8-GHz graphene-based $2-\mu \mathrm{m}$ monolithic waveguide laser," IEEE J. Select. Top. In Quantum Electron." vol. 21, 1602106, 2015.

[78] F. X. Kärtner and U. Keller, "Stabilization of solitonlike pulses with a slow saturable absorber," Opt. Lett., vol. 20, pp. 16-18, 1995.

[79] J.-C. Diels and W. Rudolf, "Femtosecond optics," in Ultrashort Laser Pulse Phenomena, 2nd ed., Burlington: Academic Press, 2006, pp. 61-142.

[80] S. Yamazoe, M. Katou, T. Adachi, and T. Kasamatsu, "Palm-top-size, $1.5 \mathrm{~kW}$ peak-power, and femtosecond (160 fs) diode-pumped modelocked $\mathrm{Yb}^{3+}: \mathrm{KY}\left(\mathrm{WO}_{4}\right)_{2}$ solid-state laser with a semiconductor saturable absorber mirror," Opt. Lett., vol. 35, pp. 748-750, 2010.

[81] S. Dhingra, J.-F. Hsu, I. Vlassiouk, and B. D’Urso, "Chemical vapour deposition of graphene on large-domain ultra-flat copper," Carbon, vol. 69, pp. 188-193, 2014.

[82] A. Choudhary, S. J. Beecher, S. Dhingra, B. D’Urso, T. L. Parsonage, J. A. Grant-Jacob, P. Hua, J. I. Mackenzie, R. W. Eason, and D. P. Shepherd, "456-mW graphene Q-switched Yb:yttria waveguide laser by evanescent-field interaction," Opt. Lett., vol. 40, pp. 1912-1915, 2015.

[83] C. G. Leburn, C. Y. Ramirez-Corral, I. J. Thomson, D. R. Hall, H. J. Baker, and D. T. Reid, "Femtosecond pulses at $50-\mathrm{W}$ average power from an Yb:YAG planar waveguide amplifier seeded by an $\mathrm{Yb}: \mathrm{KYW}$ oscillator," Opt. Express, vol. 20, pp. 17367-17373, 2012.

[84] C. R. Head, H.-Y. Chan, J. S. Feehan, D. P. Shepherd, S. U. Alam, A. C. Tropper, J. H. V. Price, and K. G. Wilcox, "Supercontinuum generation with gigahertz repetition rate femtosecond-pulse fiber-amplified VECSELs," IEEE Photon. Technol. Lett., vol.25, pp. 464-467, 2013. 


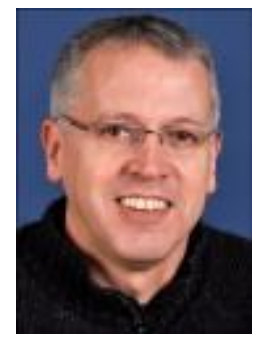

David P. Shepherd was born in Weymouth, England in 1964. He obtained a BSc and a PhD in physics from the University of Southampton in 1985 and 1989 , respectively.

He is currently a Professor at the Optoelectronics Research Centre at the University of Southampton and has over 110 journal publications in the areas of waveguide lasers, fiber lasers, solid-state lasers, optical parametric oscillators and ultrafast optics.

Professor Shepherd is a Fellow of the Optical Society of America.

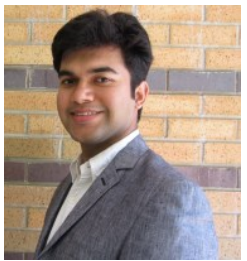

Amol Choudhary was born in Delhi, India in 1986 $\mathrm{He}$ obtained a B.Eng in Electronics and Communications from the Delhi College of Engineering, University of Delhi, India in 2008; MSc in photonics from the Gent University, Belgium and VUB, Belgium and the University of St.Andrews, Scotland in 2010; and a PhD in Optoelectronics from the Optoelectronics Research Centre (ORC), University of Southampton in 2014.

He developed ultrafast waveguide laser sources with repetition rates of up to $15 \mathrm{GHz}$ for applications in non-linear microscopy and optical frequency metrology during his PhD. In 2014 he received an EPSRC doctoral prize fellowship to work on power-scaling of mode-locked waveguide lasers and graphene pulsed waveguide laser systems. He joined the Centre for Ultrahigh bandwidth Devices for Optical Systems (CUDOS), School of Physics at the University of Sydney in May 2015. He has more than 10 Journal publications.

Dr. Choudhary is a member of SPIE and the Optical Society of America.

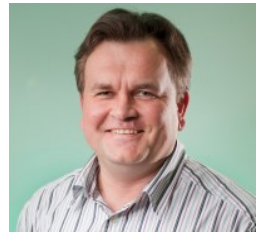

Alexander A. Lagatsky was born in Minsk, USSR in 1973. He received his Ph.D. degree in laser physics and optics in 1998 from B.I. Stepanov Institute of Physics, National Academy of Science of Belarus.

In 2001 he joined Ultrashort-pulse laser research group at the School of Physics \& Astronomy, University of St Andrews, Scotland, where he worked as a Research Fellow till 2013. Since October 2013 he is a Senior Researcher at the Fraunhofer Centre for Applied Photonics in Glasgow. His current research interests include development and application of ultrashort pulse laser sources. He is co-author of more than 100 scientific publications among which more than 50 peer-reviewed journal articles.

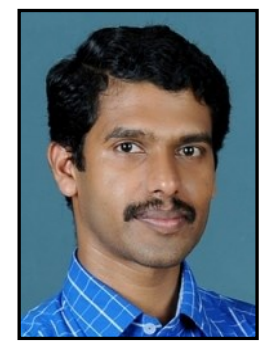

Pradeesh Kannan was born in Kerala, India in 1979. He obtained a B.Sc. in Physics from the University of Calicut, India in 1996; M.Sc. in Physics with Electronic Instrumentation as a special paper from the Mahatma Gandhi University, India in 2001; and a PhD in Physics from the Indian Institute of Technology Delhi (IITD), India in 2010.

He worked on the fabrication and photonics of organic-inorganic hybrid materials during his Ph.D. His post-doctoral work was on the fabrication of rare-earth/quantum dot doped glasses and fabrication of planar/channel waveguides for the development of ultrafast waveguide laser sources with high repetition rates. He joined as Asst. Professor in the Dept. of Physics, Govt. Victoria College Palakkad, Kerala, India in 2013. His area of research is in the development of photonic materials for the applications in light emitting devices and sensors. He has more than 20 Journal publications.

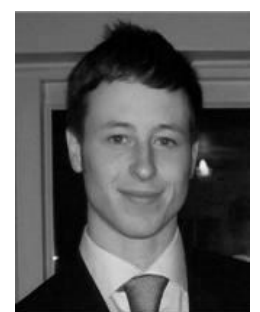

Stephen J. Beecher received a B.Sc. (Hons.) degree in physics from Imperial College London, U.K. in 2005, and an M.Sc. as a joint degree from the University of St. Andrews, U.K., and Heriot-Watt University, U.K. in 2007. He received his Ph.D. degree in physics from Heriot-Watt University in 2012.

He currently works as a Research Fellow in the Planar Waveguide and Slab Lasers group, part of the Optoelectronics Research Centre at the University of Southampton. His interests are in solid state laser physics, particularly the development and application of waveguides to realize parameter combinations that are difficult to achieve with other laser geometries.

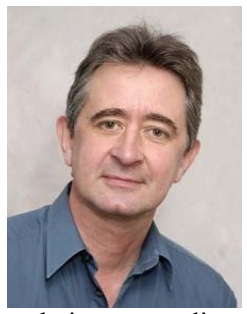

Robert W. Eason obtained a B.Sc in applied Physics from University College London in 1975, and a D.Phil in Physics from York University in 1982

$\mathrm{He}$ is a Professor of Optoelectronics at the University of Southampton, and Associate Dean Research for the Faculty of Physical Sciences and Engineering. He has been working in the area of lasers, laser-produced plasmas, photorefraction, phase conjugation, waveguide lasers, ultra-short pulse laser techniques, non-linear optics and laser-assisted thin film growth for more than 30 years, and currently runs 3 research groups in the area of laser-materials interactions. He has more than 320 publications to date.

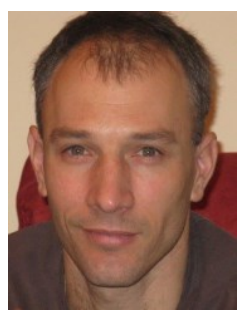

Jacob I. Mackenzie received a B.Tech. (Honors) degree from Macquarie University, Sydney, in 1994, and Ph.D. from the Optoelectronics Research Centre (ORC), University of Southampton in 2003.

$\mathrm{He}$ is Associate Professor in the ORC leading the Planar Waveguides and Slab lasers research group. Current research interests focus on the excellent thermal management properties afforded by the planar waveguide architecture and power-scalable solutions for new laser systems. This includes the investigation of visible, quasi-four-level, and challenging wavelength laser transitions.

Dr Mackenzie is a member of the SPIE and senior member of the Optical Society of America.

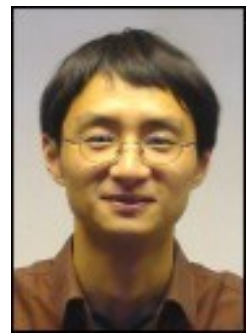

Xian Feng received the Doctor of Engineering degree in material science from the Shanghai Institute of Optics and Fine Mechanics, Chinese Academy of Sciences, Shanghai, China, in 1999.

He has worked as a postdoctoral researcher in the Faculty of Integrated Human Studies, Kyoto University, Japan, and then in Dept. of Ceramic \& Materials Engineering, Rutgers, the State University of New Jersey, USA. Since 2001, he joined the softglass group of the Optoelectronics Research Centre. He is currently a Senior Research Fellow at the ORC. His current main research interests include (1) the fabrication and the applications of microstructured optical fibers based on nonsilica optical glasses and (2) developing optical fibers with micro-/nano-composites for multiple functionalities.

Dr. Feng is a member of the Optical Society of America (OSA).

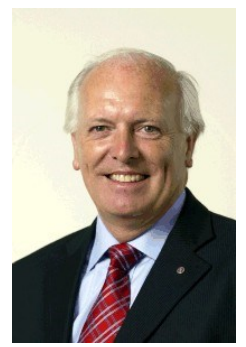

Wilson Sibbett received the B.Sc. degree in physics and $\mathrm{Ph} . \mathrm{D}$. degree in laser physics from the Queen's University, Belfast, U.K.

$\mathrm{He}$ is the Emeritus Wardlaw Professor of Physics in the School of Physics \& Astronomy at the University of St Andrews. His research career began with the generation and characterisation of picosecond laser pulses where his designs of ultrafast electron-optical streak cameras were especially noteworthy. Wilson's research group were the first to demonstrate Kerr-lens mode locking of a titanium-sapphire laser in 1989 and his interests have continued to be directed towards the development and exploitation of practical, efficient and versatile ultrashort-pulse lasers.

Professor Sibbett is a Fellow of the Royal Society (London), a Fellow of the Royal Society of Edinburgh, and has Fellowships from the Institute of Physics and the Optical Society of America.

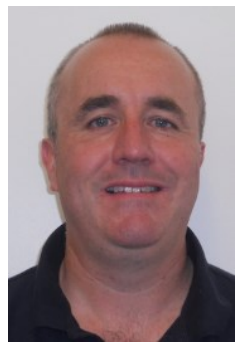

C. Tom. A. Brown was born in Lincoln, England in 1971. He obtained a BSc in Physics from Imperial College, London, U.K. in 1993 and a PhD in Physics from the Optoelectronics Research Centre (ORC), University of Southampton, U.K in 1997.

$\mathrm{He}$ is currently a Reader in Photonics at the School of Physics and Astronomy, University of St Andrews U.K. and has more than 90 journal publications in the fields of ultrafast lasers, biophotonics, medical 
applications of photonics technologies and waveguide laser devices.

Dr Brown was a co-organizer of the IEEE Summer Topicals Meeting in 2011 